\title{
Anionic Polymerization of Methyl Methacrylate Initiated with Chromium and Vanadium Ate Complexes Incorporating Diisopropylamide Ligand
}

\author{
Eiji Ihara, ${ }^{\dagger}$ Shinsuke TANAKA, Tomomichi ITOH, and Kenzo INOUE ${ }^{\dagger}$ \\ Department of Applied Chemistry, Faculty of Engineering, Venture Business Laboratory, \\ Ehime University, 3 Bunkyo-cho, Matsuyama 790-8577, Japan
}

(Received July 22, 2003; Accepted October 7, 2003)

\begin{abstract}
Anionic polymerization of methyl methacrylate (MMA) was initiated with chromium and vanadium ate complexes generated by the reaction of transition metal trichloride $\left(\mathrm{MCl}_{3}: \mathrm{M}=\mathrm{Cr}, \mathrm{V}\right)$ with $n$ equiv of lithium diisopropylamide (LDA) $(n=1-3)$ and 4- $n$ equiv of phenyllithium (PhLi). The $\mathrm{MCl}_{3} / n \mathrm{LDA} / 4-n$ PhLi systems were capable of polymerizing MMA in a living manner in tetrahydrofuran (THF) at $-78^{\circ} \mathrm{C}$, giving poly(methyl methacrylate)s (PMMA) with narrow molecular weight distributions (MWD) in high yield, where the number-average molecular weight $\left(M_{\mathrm{n}}\right)$ of the PMMAs increased proportionally with monomer to initiator feed ratio. Matrix-assisted laser desorption inonization time-of-flight mass spectrometry (MALDI-TOF-MS) revealed that the anionic polymerization was initiated by the nucleophilic attack of diisopropylamide $\left(\mathrm{iPr}_{2} \mathrm{~N}^{-}\right)$group on the transition metal center of the ate complexes and the growing species was stable under the polymerization conditions.

KEY WORDS Methyl Methacrylate / Anionic Polymerization / Transition Metal Ate Complex / Lithium Diisopropylamide (LDA) / MALDI-TOF-MS /
\end{abstract}

Although transition metal ate complexes such as organomanganates $^{1}$ and organocuprates ${ }^{2}$ have been recognized as useful reagents for organic synthesis, the number of research using the ate complexes as polymerization initiators has been limited thus far..$^{3-5}$ On the other hand, in a series of our previous studies, we have demonstrated that transition metal ate complexes generated by the reaction of transition metal halides $\left(\mathrm{MX}_{\mathrm{n}}\right)$ with organolithiums (RLi) can initiate the anionic polymerization of methyl methacrylate (MMA) to give poly(methyl methacrylate) (PMMA) in high yield. ${ }^{6-8}$ In particular, the polymerization with the ate complexes of $\mathrm{Mo},{ }^{7} \mathrm{~W},{ }^{7} \mathrm{Mn},{ }^{6,8} \mathrm{Fe},{ }^{8}$ and $\mathrm{Co}^{8}$ proceeded in a living manner in the presence of an excess of triisobutylaluminum $\left(\mathrm{iBu}_{3} \mathrm{Al}\right)$ in toluene at $0{ }^{\circ} \mathrm{C}$ for $1 \mathrm{~h}$, furnishing PMMAs with narrow molecular weight distributions (MWD) quantitatively, where the numberaverage molecular weight $\left(M_{\mathrm{n}}\right)$ of the PMMAs could be controlled by adjusting the monomer to initiator ([M]/[I]) ratio, up to $M_{\mathrm{n}}>100000$. However, although the initiating systems using the excess of $\mathrm{iBu}_{3} \mathrm{Al}$ were quite effective to control $M_{\mathrm{n}}$ and $M_{\mathrm{w}} / M_{\mathrm{n}}$ of the resulting PMMAs, the tacticity of the PMMAs was the same as that of PMMA obtained by conventional radical polymerization $(r r=\sim 67 \%)$ and the structure of the actual propagating species was ambiguous because of the presence of $\mathrm{iBu}_{3} \mathrm{Al}$. Thus, we have been trying to find an initiating system that can control the polymerization even in the absence of the aluminum compound. As such an example, we will herein report that

${ }^{\dagger}$ To whom correspondence should be addressed. chromium and vanadium ate complexes incorporating diisopropylamide $\left(\mathrm{Pr}_{2} \mathrm{~N}^{-}\right)$group as a ligand are able to polymerize MMA in a living manner in tetrahydrofuran (THF) at $-78^{\circ} \mathrm{C}$.

\section{EXPERIMENTAL}

\section{Materials}

MMA (Nacalai, 99\%) was distilled from $\mathrm{CaH}_{2}$ before use. THF was distilled from $\mathrm{Na} / \mathrm{K}$ alloy before use. $\mathrm{PhLi}$ was purchased from Kanto Chemical Co., Inc. as a cyclohexane-diethyl ether solution $(0.94 \mathrm{M})$. Diisopropylamine (Wako Pure Chemical Industries, Ltd., 98\%) and 1,1,1,3,3,3-hexamethyldisilazane (HMDS) (Tokyo Kasei Kogyo Co., Ltd., 96\%) were dried over $\mathrm{CaCl}_{2}$ and used without further purification. Chromium trichloride $\left(\mathrm{CrCl}_{3}\right)$ (Aldrich, 99\%) and vanadium trichloride $\left(\mathrm{VCl}_{3}\right)$ (strem, $\left.95 \%\right)$ were used as received.

General Polymerization Procedure (The Procedure for Run 3 in Table I)

Under a $\mathrm{N}_{2}$ atmosphere, $\mathrm{PhLi}(0.94 \mathrm{M}$ solution, $0.47 \mathrm{~mL}, 0.44 \mathrm{mmol})$ was added to a THF $(5 \mathrm{~mL})$ solution of diisopropylamine $(0.060 \mathrm{~mL}, 0.43 \mathrm{mmol})$ in a Schlenk tube at $0^{\circ} \mathrm{C}$ and the mixture was stirred for $0.5 \mathrm{~h}$ at $0{ }^{\circ} \mathrm{C}$. The resulting solution of lithium diisopropylamide (LDA) was added to a suspension of $\mathrm{CrCl}_{3}$ $(23.5 \mathrm{mg}, 0.148 \mathrm{mmol})$ in THF $(5 \mathrm{~mL})$ cooled at $0{ }^{\circ} \mathrm{C}$ in a Schlenk tube, and the resulting mixture was stirred for $2 \mathrm{~h}$ at room temperature. After it was cooled to $0{ }^{\circ} \mathrm{C}$, an additional 1 equiv of $\mathrm{PhLi}(0.94 \mathrm{M}$ solution, 
Polymerization of MMA with Ate Complexes of $\mathrm{Cr}$ and $\mathrm{V}$

Table I. Polymerization of MMA with Chromium Ate Complexes ${ }^{\mathrm{a}}$

\begin{tabular}{|c|c|c|c|c|c|c|}
\hline Run & Initiating System & {$[\mathrm{M}] /[\mathrm{I}]$} & $\begin{array}{c}\text { Reaction } \\
\text { Temperature }\left({ }^{\circ} \mathrm{C}\right) \\
\end{array}$ & $\begin{array}{l}\text { Yield } \\
(\%) \\
\end{array}$ & $M_{\mathrm{n}}^{\mathrm{b}}$ & $M_{\mathrm{w}} / M_{\mathrm{n}}^{\mathrm{b}}$ \\
\hline 1 & $\mathrm{CrCl}_{3} / 3 \mathrm{LDA}$ & 102 & -78 & trace & - & - \\
\hline 2 & $\mathrm{CrCl}_{3} / 3 \mathrm{LDA} / \mathrm{PhLi}$ & 52 & -78 & 100 & 18100 & 1.03 \\
\hline 3 & $\mathrm{CrCl}_{3} / 3 \mathrm{LDA} / \mathrm{PhLi}$ & 100 & -78 & 100 & 27700 & 1.02 \\
\hline 4 & $\mathrm{CrCl}_{3} / 3 \mathrm{LDA} / \mathrm{PhLi}$ & 151 & -78 & 100 & 38600 & 1.04 \\
\hline 5 & $\mathrm{CrCl}_{3} / 3 \mathrm{LDA} / \mathrm{PhLi}$ & 202 & -78 & 100 & 56500 & 1.04 \\
\hline $6^{\mathrm{c}}$ & $\mathrm{CrCl}_{3} / 3 \mathrm{LDA} / \mathrm{PhLi}$ & 100 & 0 & 32 & 30600 & 1.75 \\
\hline 7 & $\mathrm{CrCl}_{3} / 2 \mathrm{LDA} / 2 \mathrm{PhLi}$ & 100 & -78 & 100 & 33400 & 1.05 \\
\hline 8 & $\mathrm{CrCl}_{3} / \mathrm{LDA} / 3 \mathrm{PhLi}$ & 100 & -78 & 21 & 216800 & 2.58 \\
\hline 9 & $\mathrm{CrCl}_{3} / 4 \mathrm{PhLi}$ & 102 & -78 & 7 & 162000 & 1.96 \\
\hline 10 & $\mathrm{CrCl}_{3} / 3 \mathrm{HMDS}^{\mathrm{d}} / \mathrm{PhLi}$ & 100 & -78 & 72 & bimodal & - \\
\hline
\end{tabular}

$0.16 \mathrm{~mL}, 0.15 \mathrm{mmol}$ ) was added and the resulting mixture was stirred for $1 \mathrm{~h}$ at $0{ }^{\circ} \mathrm{C}$ to generate the ate complex $\left[\left(\mathrm{iPr}_{2} \mathrm{~N}\right)_{3} \mathrm{CrPh}\right]^{-} \mathrm{Li}^{+}$. After the mixture was cooled to $-78^{\circ} \mathrm{C}$ using a dry-ice/methanol bath, the polymerization was started by injecting MMA $(1.60 \mathrm{~mL}$, $15.0 \mathrm{mmol}$ ) dropwise by a syringe, and the resulting mixture was stirred for $3 \mathrm{~h}$ at $-78^{\circ} \mathrm{C}$. To quench the polymerization, $2.5 \mathrm{~mL}$ of $\mathrm{MeOH}$ was added to the mixture at $-78^{\circ} \mathrm{C}$, and it was warmed to room temperature. After volatiles were removed under reduced pressure, the residual solid was dissolved into $60 \mathrm{~mL}$ of $\mathrm{CHCl}_{3}$ and purified by washing with $60 \mathrm{~mL}$ of $1 \mathrm{~N} \mathrm{HCl}$ and $120 \mathrm{~mL}$ of $\mathrm{H}_{2} \mathrm{O}$. After the solvent was removed under reduced pressure, the resulting white solid was dried under vacuum for $8 \mathrm{~h}$ at $40^{\circ} \mathrm{C}$ to give PMMA in quantitative yield.

Other polymerizations were carried out in similar manners. PMMAs were purified by either the extractive method described above or reprecipitation from $\mathrm{CHCl}_{3}$ into $\mathrm{MeOH}$.

\section{Measurements}

${ }^{1} \mathrm{H}$ NMR spectra were recorded on a Brucker Avance 400 spectrometer with tetramethylsilane (TMS) as an internal standard in chloroform- $d\left(\mathrm{CDCl}_{3}\right)$ at $25^{\circ} \mathrm{C}$. The tacticity of PMMA was determined from the integral ratio of $\mathrm{C}-\mathrm{CH}_{3}$ signals, which separated into three peaks with respect to the $m m(1.21 \mathrm{ppm}), \mathrm{mr}$ $(1.02 \mathrm{ppm})$, and $r r(0.83 \mathrm{ppm})$ triads. $M_{\mathrm{n}}$ 's and MWDs were measured by means of gel-permeation-chromatography (GPC) on a Jasco Bowin system (version 1.50) equipped with a differential refractometer detector with THF as an eluent at a flow rate of $1.0 \mathrm{~mL} \mathrm{~min}^{-1}$ and calibrated with PMMA standards (Shodex M-75, $\left.M_{\mathrm{n}}=2190-653000, M_{\mathrm{w}} / M_{\mathrm{n}}=1.03-1.08\right)$. MALDITOF-MS analyses were performed on a PerSeptive Biosystems Voyager RP, and the samples for the analyses were prepared according to the method described in the literature, ${ }^{9}$ with 1,8 -dihydroxy- $9(10 \mathrm{H})$ anthracenone (Nacalai) as a matrix, with sodium trifluoroacetate (Tokyo Kasei Kogyo Co., Ltd.) as a cationizing agent, and with Angiotensin I (human; molecular weight $=1296.5$; SIGMA) and insulin (bovine pancreas; molecular weight $=5733.50$; Nacalai) as internal standards for calibration.

\section{RESULTS AND DISCUSSION}

The reaction of $\mathrm{CrCl}_{3}$ with 3 equiv of LDA in tetrahydrofuran (THF) has been reported to give tris(diisopropylamide)chromium $\left[\left(\mathrm{iPr}_{2} \mathrm{~N}\right)_{3} \mathrm{Cr}\right] .{ }^{10}$ When MMA (100 equiv with respect to $\mathrm{Cr}$ ) was added to a mixture of $\mathrm{CrCl}_{3}$ and 3 equiv of LDA in THF at $-78^{\circ} \mathrm{C}$, which was supposed to contain $\left(\mathrm{iPr}_{2} \mathrm{~N}\right)_{3} \mathrm{Cr}$ and $\mathrm{LiCl}$, no polymerization occurred at all. This result indicates that $\mathrm{Pr}_{2} \mathrm{~N}^{-}$groups on the neutral chromium complex are not nucleophilic enough to initiate the polymerization of MMA. However, by the addition of 1 equiv of $\mathrm{PhLi}$ to the mixture, we succeeded in generating a new initiating system (the $\mathrm{CrCl}_{3} / 3 \mathrm{LDA} / \mathrm{PhLi}$ system), which effectively induced living polymerization of MMA in THF at $-78^{\circ} \mathrm{C}$. For example, the polymerization of MMA (100 equiv with respect to $\mathrm{CrCl}_{3}$ ) with the $\mathrm{CrCl}_{3} / 3 \mathrm{LDA} / \mathrm{PhLi}$ system in THF at $-78^{\circ} \mathrm{C}$ for $3 \mathrm{~h}$ resulted in the formation of a PMMA with a narrow $\operatorname{MWD}\left(M_{\mathrm{n}}=27700, M_{\mathrm{w}} / M_{\mathrm{n}}=1.02\right)$ (run 3, Table I). Since as with the neutral complex $\left(\mathrm{iPr}_{2} \mathrm{~N}\right)_{3} \mathrm{Cr}, \mathrm{PhLi}$ alone were not capable of initiating the polymerization of MMA in our experiment, we can assume that the reaction of $\mathrm{PhLi}$ with $\left(\mathrm{iPr}_{2} \mathrm{~N}\right)_{3} \mathrm{Cr}$ resulted in the formation of an chromium ate complex $\left[\left(\mathrm{ir}_{2} \mathrm{~N}\right)_{3} \mathrm{CrPh}\right]^{-} \mathrm{Li}^{+}$, which effectively initiated the polymerization in the presence of 3 equiv of $\mathrm{LiCl}$ generated in situ during the formation of $\left(\mathrm{iPr}_{2} \mathrm{~N}\right)_{3} \mathrm{Cr}$. Since the isolation of the ate 
complex $\left[\left(\mathrm{iPr}_{2} \mathrm{~N}\right)_{3} \mathrm{CrPh}\right]^{-} \mathrm{Li}^{+}$is technically difficult for us, it is not clear whether the presence of the 3 equiv of $\mathrm{LiCl}$ is essential for the controlled polymerization or not.

To determine which ligand initiated the polymerization, either $\mathrm{iPr}_{2} \mathrm{~N}^{-}$or $\mathrm{Ph}^{-}$, MALDI-TOF-MS analyses of a low molecular weight PMMA $\left(M_{\mathrm{n}}=5100\right.$, $\left.M_{\mathrm{w}} / M_{\mathrm{n}}=1.04\right)$ obtained by the $\mathrm{CrCl}_{3} / 3 \mathrm{LDA} / \mathrm{PhLi}$ system were carried out. The spectrum observed by the analysis in linear mode shown in Figure 1 (a) exhibits one main set of peaks with an interval of the molecular weight of MMA $(\mathrm{m} / \mathrm{z}=100.1)$, indicating that the
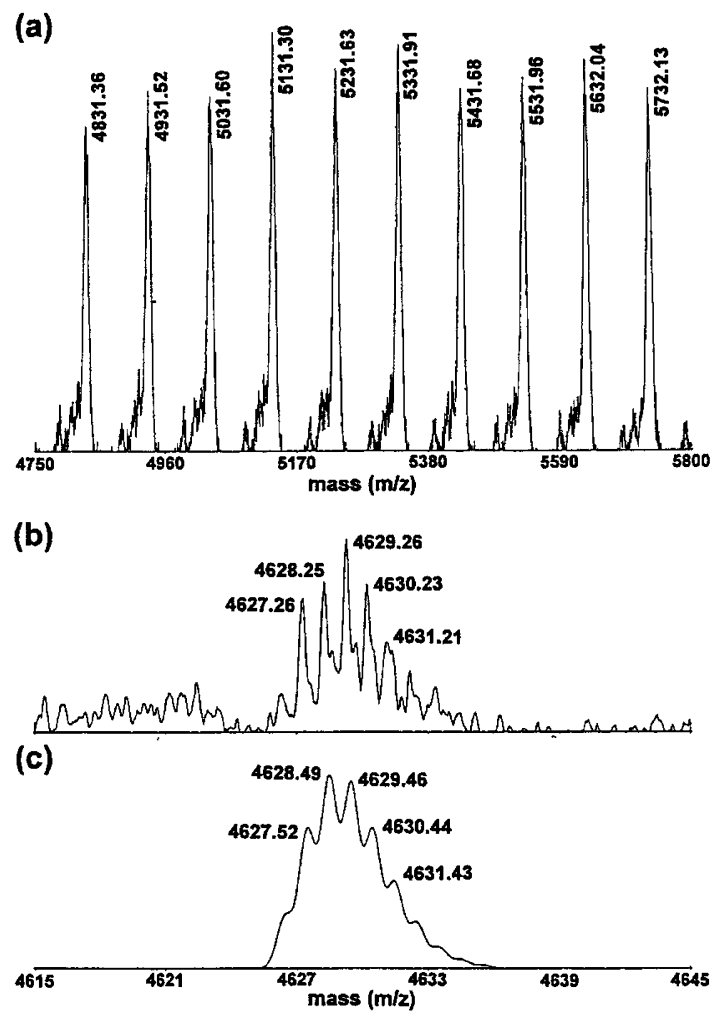

Figure 1. MALDI-TOF-MS spectra of PMMA obtained with the $\mathrm{CrCl}_{3} / 3 \mathrm{LDA} / \mathrm{PhLi}$ system in (a) linear mode and (b) reflector mode and (c) the theoretical isotopic distribution of the $\mathrm{Na}^{+}$adduct of the 45-mer of MMA with $\operatorname{iPr}_{2} \mathrm{~N}$ at $\alpha$-chain end and $\mathrm{H}$ at $\omega$-chain end. polymerization proceeded primarily via one propagating species. Figure 1(b) shows one of the peaks around $m / z=4630$ in the spectrum observed in the MS analysis in reflector mode, which is in good agreement with the theoretical isotopic distribution of the $\mathrm{Na}^{+}$adduct of 45-mer of MMA bearing $\operatorname{iPr}_{2} \mathrm{~N}$ at the $\alpha$-chain end and $\mathrm{H}$ at $\omega$-chain end shown in Figure 1 (c). The results clearly establish that the polymerization was initiated by the nucleophilic attack of one of the three $\operatorname{iPr}_{2} \mathrm{~N}^{-}$ groups on the $\mathrm{Cr}$ center of the initiating ate complex as illustrated in Scheme 1.

As can be seen from runs 2-5 in Table I and Figure 2, when various monomer to initiator $([\mathrm{M}] /[\mathrm{I}])$ ratios were applied for the polymerization, the $M_{\mathrm{n}}$ of the resulting PMMA increased linearly with increase of the $[\mathrm{M}] /[\mathrm{I}]$ ratio while the narrow MWDs remained intact. Although the initiator efficiency (IE) calculated based on the assumption that one polymer chain was produced per $\left[\left(\mathrm{iPr}_{2} \mathrm{~N}\right)_{3} \mathrm{CrPh}\right]^{-} \mathrm{Li}^{+}$molecule is somewhat low $(\sim 30-40 \%)$, it is possible to control the $M_{\mathrm{n}}$ of the

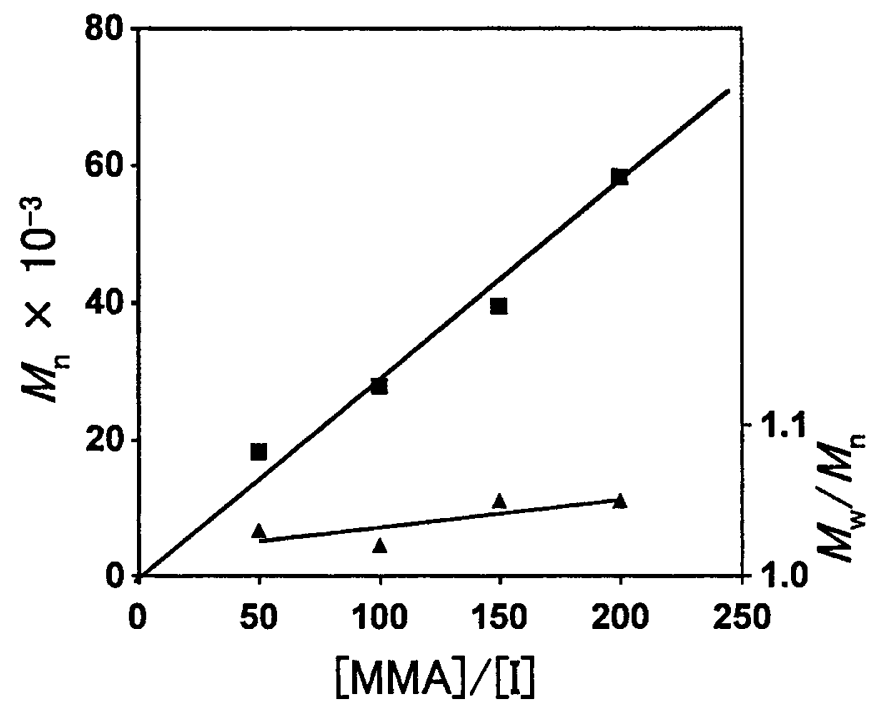

Figure 2. Plots of $M_{\mathrm{n}}(\boldsymbol{\bullet})$ and $M_{\mathrm{w}} / M_{\mathrm{n}}(\mathbf{\Delta})$ versus [M]/[I] ratio for the polymerization of MMA initiated with the $\mathrm{CrCl}_{3} / 3$ LDA/PhLi system.<smiles>CC(C)N([O-])C(C)C</smiles>

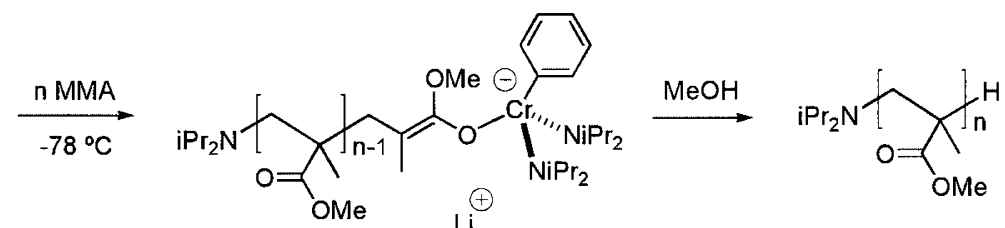

Scheme 1. 

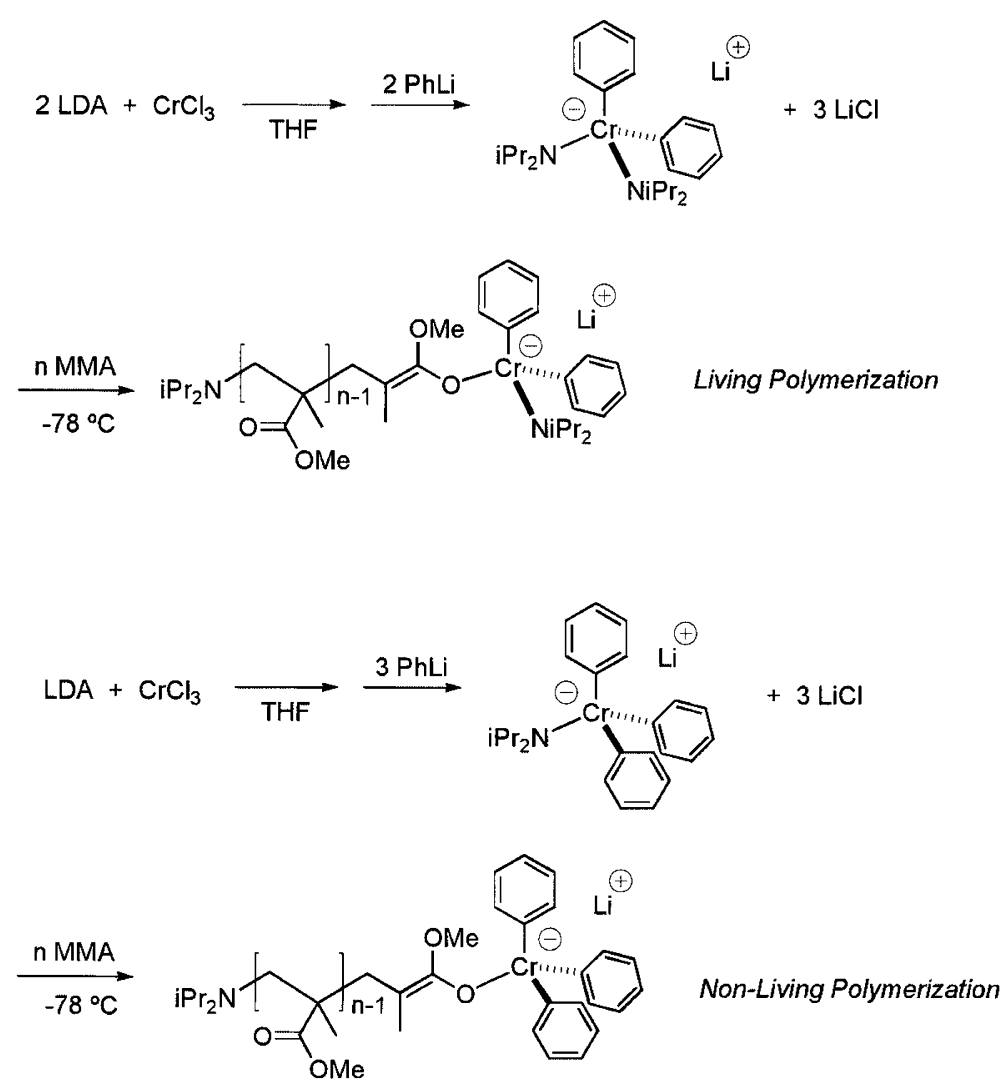

Scheme 2.

PMMAs by changing the $([\mathrm{M}] /[\mathrm{I}])$ ratio, since the IE values are almost constant regardless of the $[\mathrm{M}] /[\mathrm{I}]$ ratio.

By changing the molar ratio of LDA and $\mathrm{PhLi}$ employed for the reaction with $\mathrm{CrCl}_{3}$, we can prepare the ate complexes with different combinations of $\mathrm{iPr}_{2} \mathrm{~N}$ and $\mathrm{Ph}$ as ligands. For example, the reaction of 2 equiv of LDA with $\mathrm{CrCl}_{3}$ followed by the addition of 2 equiv of $\mathrm{PhLi}$ (the $\mathrm{CrCl}_{3} / 2 \mathrm{LDA} / 2 \mathrm{PhLi}$ system) should result in the formation of an ate complex $\left[\left(\mathrm{iPr}_{2} \mathrm{~N}\right)_{2} \mathrm{CrPh}_{2}\right]^{-} \mathrm{Li}^{+}$, which also polymerized MMA in a living manner (run 7, Table I). On the other hand, the $\mathrm{CrCl}_{3} / \mathrm{LDA} / 3 \mathrm{PhLi}$ system consisting the chromium ate complex with one $i \mathrm{Pr}_{2} \mathrm{~N}$ group $\left[\left(\mathrm{Pr}_{2} \mathrm{~N}\right) \mathrm{CrPh}_{3}\right]^{-} \mathrm{Li}^{+}$ gave a PMMA with a broad MWD in low yield (run 8, Table I). A mixture of $\mathrm{CrCl}_{3}$ and 4 equiv of $\mathrm{PhLi}$ (the $\mathrm{CrCl}_{3} / 4 \mathrm{PhLi}$ system), which was supposed to contain an ate complex $\left(\mathrm{Ph}_{4} \mathrm{Cr}\right)^{-} \mathrm{Li}^{+}$, also failed to control the polymerization with respect to $M_{\mathrm{n}}$ and $M_{\mathrm{w}} / M_{\mathrm{n}}$ (run 9, Table I). Since the $\mathrm{iPr}_{2} \mathrm{~N}^{-}$rather than $\mathrm{Ph}^{-}$would participate in the initiation with $\left[\left(\mathrm{iPr}_{2} \mathrm{~N}\right)_{2} \mathrm{CrPh}_{2}\right]^{-} \mathrm{Li}^{+}$ and $\left[\left(\mathrm{iPr}_{2} \mathrm{~N}\right) \mathrm{CrPh}_{3}\right]^{-} \mathrm{Li}^{+}$as well as the initiation with $\left[\left({ }^{2} r_{2} \mathrm{~N}\right)_{3} \mathrm{CrPh}\right]^{-} \mathrm{Li}^{+}$described above, the presence of at least one $i \operatorname{Pr}_{2} \mathrm{~N}$ moiety on the chromium center of the propagating species is essential to realize the living polymerization by these initiating systems where the amide ligand probably stabilize the propagating species sterically and/or electronically (Scheme 2). The abovedescribed dependence of the polymerization behavior of MMA on the structure of the ate complexes suggests that the propagation actually proceeds on the chromium ate complexes.

The polymerization with the $\mathrm{CrCl}_{3} / 3 \mathrm{LDA} / \mathrm{PhLi}$ system did not proceed in a living manner at $0{ }^{\circ} \mathrm{C}$, giving a PMMA with a broad MWD in low yield (run 6, Table I). The use of 1,1,1,3,3,3-hexamethyldisilazane (HMDS) in place of $\mathrm{ir}_{2} \mathrm{NH}$ resulted in the formation of a bimodal polymer (run 10, Table I). Although we have expected that the incorporation of the transition metal moiety into the growing end would give a significant influence on the stereochemical course of the propagation, tacticity of the PMMAs obtained with these systems is usual (syndiotactic) for the anionic polymerization of MMA in THF at low temperature (eg. run 3 in Table I, $m m: m r: r r=2: 22: 76$ ).

Next, vanadium trichloride $\left(\mathrm{VCl}_{3}\right)$ was used as a transition metal halide instead of $\mathrm{CrCl}_{3}$, where polymerization did not occur by the addition of MMA to a mixture of $\mathrm{VCl}_{3}$ and 3 equiv of LDA, which was supposed to contain the neutral $\left[\left(\mathrm{Pr}_{2} \mathrm{~N}\right)_{3} \mathrm{~V}\right]$ and $\mathrm{LiCl}^{11}$ However, in a similar manner described above for the chromium complexes, the ate complexes bearing $\operatorname{iPr}_{2} \mathrm{~N}$ and $\mathrm{Ph}$ as ligands were capable of polymerizing MMA in a living manner: the $\mathrm{VCl}_{3} / 3 \mathrm{LDA} / \mathrm{PhLi}$ system and 

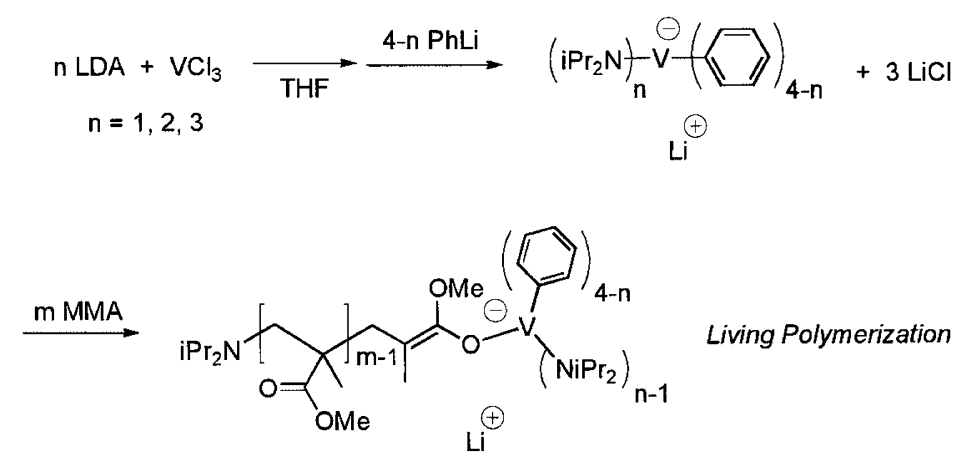

Scheme 3.

Table II. Polymerization of MMA with Vanadium Ate Complexes ${ }^{\mathrm{a}}$

\begin{tabular}{ccccccc}
\hline Run & Initiating System & {$[\mathrm{M}] /[\mathrm{I}]$} & $\begin{array}{c}\text { Temperature } \\
\left({ }^{\circ} \mathrm{C}\right)\end{array}$ & $\begin{array}{c}\text { Yield } \\
(\%)\end{array}$ & $M_{\mathrm{n}}{ }^{\mathrm{b}}$ & $M_{\mathrm{w}} / M_{\mathrm{n}}{ }^{\mathrm{b}}$ \\
\hline 1 & $\mathrm{VCl}_{3} / 3 \mathrm{LDA}$ & 102 & -78 & trace & - & - \\
2 & $\mathrm{VCl}_{3} / 3 \mathrm{LDA} / \mathrm{PhLi}$ & 101 & -78 & 99 & 29600 & 1.13 \\
3 & $\mathrm{VCl}_{3} / 2 \mathrm{LDA} / 2 \mathrm{PhLi}$ & 100 & -78 & 91 & 14100 & 1.12 \\
4 & $\mathrm{VCl}_{3} / \mathrm{LDA} / 3 \mathrm{PhLi}$ & 100 & -78 & 99 & 18300 & 1.06 \\
5 & $\mathrm{VCl}_{3} / 4 \mathrm{PhLi}$ & 101 & -78 & 100 & 369000 & 1.22 \\
6 & $\mathrm{VCl}_{3} / 3 \mathrm{HMDS}^{\mathrm{c}} / \mathrm{PhLi}$ & 102 & -78 & 12 & 527200 & 1.50 \\
\hline
\end{tabular}

${ }^{\mathrm{a} C}$ Conditions: $14.9-32.2 \mathrm{mg}(0.0947-0.205 \mathrm{mmol}) \mathrm{VCl}_{3}$ in $10 \mathrm{~mL}$ THF for $3 \mathrm{~h}$. ${ }^{\mathrm{b}}$ Estimated by GPC based on PMMA standards. ${ }^{\mathrm{c}} \mathrm{HMDS}=1,1,1,3,3,3$-hexamethyldisilazane.

the $\mathrm{VCl}_{3} / 2 \mathrm{LDA} / 2 \mathrm{PhLi}$ system containing ate complexes $\left[\left(\mathrm{iPr}_{2} \mathrm{~N}\right)_{3} \mathrm{VPh}\right]^{-} \mathrm{Li}^{+}$and $\left[\left(\mathrm{iPr}_{2} \mathrm{~N}\right)_{2} \mathrm{VPh}_{2}\right]^{-} \mathrm{Li}^{+}$respectively, gave PMMAs with narrow MWDs in high yield (runs 2 and 3, Table II). In addition, the initiating system generated from 1 equiv of LDA and 3 equiv of $\mathrm{PhLi}$ (the $\mathrm{VCl}_{3} / \mathrm{LDA} / 3 \mathrm{PhLi}$ system) also induced living polymerization of MMA (run 4, Table II), which was in sharp contrast to the case of chromium where the similar system failed to control the polymerization (run 8, Table I). Accordingly, the stability of the propagating end having $\mathrm{VPh}_{3}$ moiety should be higher than that of the chromium counterpart.

The initiation by the nucleophilic attack of $\mathrm{iPr}_{2} \mathrm{~N}^{-}$ group was confirmed for the polymerization with the $\mathrm{VCl}_{3} / \mathrm{LDA} / 3 \mathrm{PhLi} /$ system by the MALDI-TOF-MS analysis of a low molecular weight PMMA $\left(M_{\mathrm{n}}=5100\right.$, $\left.M_{\mathrm{w}} / M_{\mathrm{n}}=1.04\right)$ obtained with this system as shown in Figure 3, where a good agreement is observed between one of the peaks appearing around $\mathrm{m} / \mathrm{z}=2525$ in the spectrum measured in reflector mode [Figure $3(b)$ ] and the theoretical isotopic distribution of the $\mathrm{Na}^{+}$adduct of 24-mer of MMA having $i_{2}{ }_{2} \mathrm{~N}$ group and $\mathrm{H}$ at $\alpha$ - and $\omega$-chain end respectively [Figure 3 (c)]. The origin of the minor peaks observed in lower molecular weight regions of each main peak in the spectrum in linear mode [Figure 3 (a)] could be attributed to PMMAs having $\mathrm{H}^{+}$ instead of $\mathrm{Na}^{+}$in a form of an ammonium salt, because the difference of $m / z$ values between the main peaks and the minor peaks is close to the atomic weight of $\mathrm{Na}$.
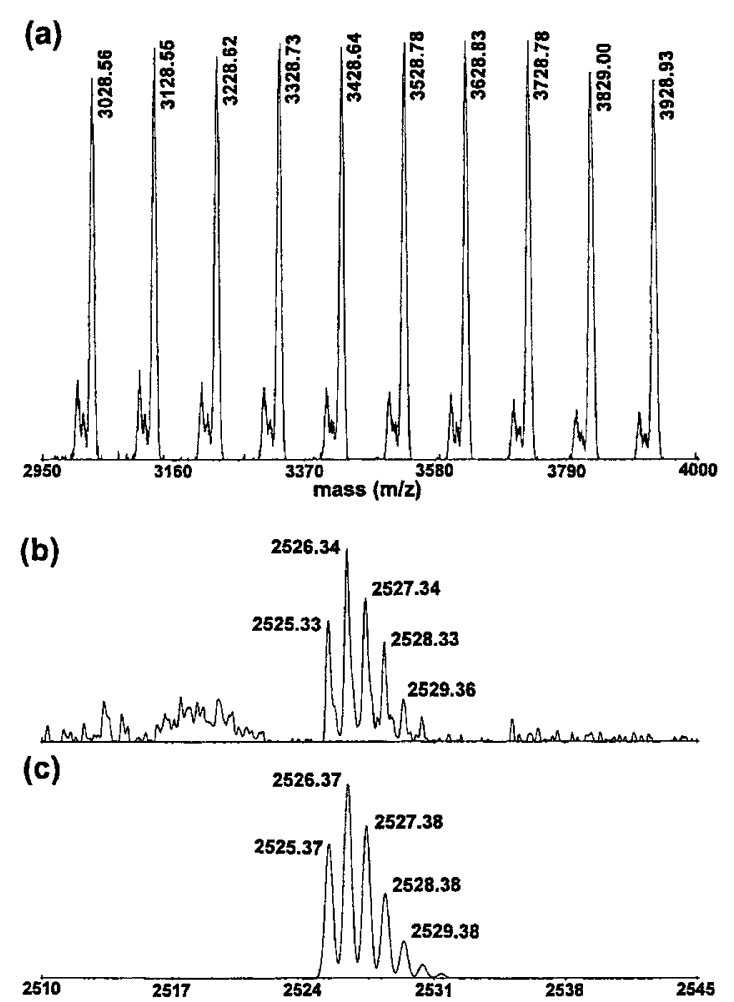

Figure 3. MALDI-TOF-MS spectra of PMMA obtained with the $\mathrm{VCl}_{3} / \mathrm{LDA} / 3 \mathrm{PhLi}$ system in (a) linear mode and (b) reflector mode and (c) the theoretical isotopic distribution of the $\mathrm{Na}^{+}$adduct of the 24-mer of MMA with $\operatorname{Pr}_{2} \mathrm{~N}$ at $\alpha$-chain end and $\mathrm{H}$ at $\omega$-chain end. 


\section{CONCLUSIONS}

We have demonstrated that the ate complexes of chromium and vanadium bearing $\operatorname{iPr}_{2} \mathrm{~N}$ and $\mathrm{Ph}$ as ligands can act as initiators for a living polymerization of MMA giving narrow MWD PMMAs in high yield. It was revealed by MALDI-TOF-MS analysis that the polymerization was initiated by the nucleophilic attack of $\mathrm{iPr}_{2} \mathrm{~N}^{-}$. Although it has been reported that LDA itself can conduct the living polymerization of MMA in $\mathrm{THF}$ at $-78^{\circ} \mathrm{C}$ in the presence of an excess of $\mathrm{LiCl}$ to give PMMAs with narrow MWDs, ${ }^{12-14}$ we are expecting that there will be some polymerization systems in which the presence of the transition metal moiety in the propagating end would result in characteristic polymerization behavior such as living and/or stereospecific polymerization for various monomers. The attempts to find such polymerization systems by using various combinations of transition metals and ligands are underway in our laboratory.

Acknowledgments. This work was supported by Grant-in-Aid (No. 15036251, for Scientific Research on Priority Areas "Reaction Control of Dynamic Complexes" and No. 15350071) from Ministry of Education, Culture, Sports, Science and Technology, Japan.

\section{REFERENCES}

1. K. Oshima, J. Organomet. Chem., 575, 1 (1999).
2. B. H. Lipshutz, "Comprehensive Organometallic Chemistry II”, E. W. Abel, F. G. A. Stone, and G. Wilkinson, Ed., Elsevier Science, Ltd., New York, N.Y., 1995, vol. 12, p59.

3. S. Kawaguchi, E. Nomura, and K. Ito, Polym. J., 30, 546 (1998).

4. J. J. Eisch and J. R. Alila, Organometallics, 19, 1211 (2000).

5. D. Mardare and K. Matyjaszewski, Macromol. Chem. Phys., 196, (1995).

6. E. Ihara, T. Todaka, and K. Inoue, Macromol. Rapid. Commun., 23, 64 (2002).

7. E. Ihara, S. Tanaka, and K. Inoue, J. Polym. Sci., Part A: Polym. Chem., 40, 4302 (2002).

8. E. Ihara, S. Todaka, and K. Inoue, J. Polym. Sci., Part A: Polym. Chem., 41, 1962 (2003).

9. H. Nonaka, M. Ouchi, M. Kamigaito, and M. Sawamoto, Macromolecules, 34, 2083 (2001).

10. E. C. Alyea, J. S. Basi, D. C. Bradley, and M. H. Chisholm, J. Chem. Soc., Chem. Commun., 495 (1968).

11. Synthesis of $\mathrm{V}(\mathrm{THF})(\mathrm{Cl})\left(\mathrm{NRAr}_{\mathrm{F}}\right)_{2}\left(\mathrm{R}=\mathrm{C}\left(\mathrm{CD}_{3}\right)_{2} \mathrm{CH}_{3}, \mathrm{Ar}_{\mathrm{F}}=2\right.$, $\left.5-\mathrm{C}_{6} \mathrm{H}_{3} \mathrm{FMe}\right)$ by the reaction of $\mathrm{VCl}_{3}$ with 2 equiv of $\mathrm{Li}\left(\mathrm{NRAr}_{\mathrm{F}}\right)\left(\mathrm{OEt}_{2}\right)$ in THF has been reported. References:

M. G. Fickes, W. M. Davis, and C. C. Cummins, J. Am. Chem. Soc., 117, 6384 (1995).

12. T. E. Long, R. A. Guistina, B. A. Schell, and J. E. McGrath, J. Polym. Sci., Part A: Polym. Chem., 32, 2425 (1994).

13. S. Antoun, Ph. Teyssié, and R. Jérôme, Macromolecules, 30, 1556 (1997).

14. S. Antoun, Ph. Teyssié, and R. Jérôme, J. Polym. Sci., Part A: Polym. Chem., 35, 3637 (1997). 